\title{
New developments in the management of major depressive disorder and generalized anxiety disorder: role of quetiapine
}

\author{
Bernhard T Baune \\ Department of Psychiatry, School \\ of Medicine, James Cook University, \\ Queensland 48II, Australia
}

\begin{abstract}
Quetiapine has demonstrated efficacy in schizophrenia, bipolar disorder and in the treatment of specific symptom clusters such as agitation and sleep problems in mood disorders. In this review, randomized controlled studies demonstrating efficacy, safety and tolerability of quetiapine in major depressive disorder (MDD) and general anxiety disorder (GAD) are evaluated. The results show that quetiapine monotherapy and quetiapine augmentation of antidepressant treatment in MDD and GAD are efficacious for short-term and maintenance treatment at a dose range between 50 and $300 \mathrm{mg}$ /day. Quetiapine appears to have a specific but overall mild side-effect profile, though, some adverse effects such as sedation and somnolence may lead to withdrawal from treatment in some patients. Overall, the available evidence suggests that there is a significant role for quetiapine in the treatment of MDD and GAD.
\end{abstract}

Keywords: quetiapine, major depressive disorders, general anxiety disorder, randomized controlled studies, adverse effects

\section{Introduction}

The enhancement of treatment response of major depressive disorder (MDD) and general anxiety disorder (GAD) is a major goal in clinical research and patient care. Clinical trials indicate that over $50 \%$ of depressed patients show an inadequate response to antidepressant therapy (Fava and Davidson 1996; Ferrier 1999) and that incomplete recovery from MDD increases the risk of both chronicity and recurrence. Recovery, which involves a complete remission of symptoms and a return to baseline psychosocial function, should be the goal of therapy (Rush and Trivedi 1995; Nierenberg and Wright 1999). Poor response to adequate antidepressant treatment has been termed 'treatment resistant depression' (TRD) (Ananth 1998). Although there is lack of agreement on a formal definition of TRD, one that is often cited defines it as a failure of response to at least two trials of antidepressant medication, at an adequate dose and duration from at least two different classes (Ananth 1998). Issues such as adherence, missed diagnosis of psychotic depression, bipolar disorder, or co-morbid anxiety should be investigated in patients who have not responded to initial therapeutic strategies (Kennedy and Lam 2003).

Beyond ensuring optimal use of the index antidepressant, treatment strategies for TRD include switching to another antidepressant, and augmentation or combination with two or more agents. In patients with TRD, adding or augmenting with lithium, tri-iodothyronine or atypical antipsychotics have demonstrated benefits (Kennedy and Lam 2003). Augmentation with atypical antipsychotics, including risperidone, olanzapine, ziprasidone, and quetiapine, has shown promising results in terms of improving remission rates (Shelton and Papakostas 2008).

The atypical antipsychotic quetiapine has shown efficacy in the treatment of positive and negative symptoms in schizophrenia (Srisurapanont et al 2004). 
Quetiapine has more recently gained attention as a clinically useful treatment option in patients with bipolar affective disorder (Calabrese et al 2005; Thase et al 2006; Keating and Robinson 2007; Weisler et al 2008b) and major depression (Todder et al 2006; Baune et al 2007) due to its mood stabilizing effects (Ghaemi and Katzow 1999; Vieta 2005).

Quetiapine and its major active human plasma metabolite, $\mathrm{N}$-desalkyl quetiapine, has shown in vitro antagonistic activity on multiple brain neurotransmitter receptors and in particular on serotonergic $\left(5 \mathrm{HT}_{2 \mathrm{~A}}\right)$, noradrenergic ( $\alpha_{1}$-adrenoreceptor) and the noradrenergic transporter, thus having a positive influence on mood (Arango and Bernardo 2005). With its anti-dopaminergic properties $\left(D_{1}, D_{2}\right)$, quetiapine is considered to evolve impact on motor activity, eg, on agitation in depression (Todder et al 2006; Dannlowski et al in press).

Quetiapine has demonstrated clinical efficacy in the past few years for clinical indications ranging from bipolar disorder (Berk and Dodd 2005; Calabrese et al 2005; Croissant et al 2006) and treatment of behavioral disturbances in dementia (Savaskan et al 2006) to the management of substance dependence disorders (Sattar et al 2004; Croissant et al 2006; Hanley and Kenna 2008). Moreover, positive effects of quetipiane on sleep architecture and sleep recovery in healthy subjects (Cohrs et al 2004) as well as its sleep promoting effects in depression (Todder et al 2006) and bipolar disorder (Sokolski and Denson 2003), have been demonstrated in recent years. Preliminary evidence suggests a role for quetiapine in managing TRD (Sagud et al 2006; Doree et al 2007) and anxiety symptoms in bipolar depression (Hirschfeld et al 2006).

These recently published studies support the view that quetiapine has a broad range of clinical use in mood disorders including major depression and symptom clusters such as agitation and sleep deterioration in mood and anxiety disorders. Although a number of reviews have examined the efficacy of quetiapine in bipolar disorder (Dando and Keating 2005; Keating and Robinson 2007; Khazaal et al 2007; Shelton and Papakostas 2008), there is no review of controlled randomized studies in MDD and GAD available to date. Most recent accumulating data on the effects of quetiapine in MDD and anxiety disorder have been substantially derived from small open-label uncontrolled studies (Philip et al 2008), since data from randomized controlled studies were not available, such as for quetiapine as augmentation therapy for depression or anxiety (Nemeroff 2005).
A review of randomized and controlled studies focusing on the efficacy, safety and tolerability, and patient outcomes, such as quality of life, patient satisfaction and adherence for quetiapine treatment of MDD and GAD, would be of use to the clinical and research orientated reader. This review evaluates the recently available randomized controlled studies on quetiapine in MDD and GAD (Philip et al 2008) and goes beyond the mostly open-label studies published on quetiapine in TRD or unipolar depression (Nemeroff 2005; Gao et al 2006; Doree et al 2007).

\section{Method}

Studies were identified using searches of Pubmed/Medline. Searches were conducted by cross-referencing the term 'major depressive disorder (MDD)' or 'general anxiety disorder (GAD)' with 'quetiapine'. Restriction to the minimum criteria of double-blind, randomized, placebo controlled studies published in the English language was used. These searches were then repeated using EMBase and the Cochrane databases as well. We also searched the abstracts of major psychiatric meetings held since 2000 (American Psychiatric Association; New Clinical Drug Evaluation Unit of the National Institutes of Mental Health; American College of Neuropsychopharmacology; European College of Neuropsychopharmacology; Collegium Internationale Neuropsychopharmacologicum; Society of Biological Psychiatry, World Federation of Societies of Biological Psychiatry; World Psychiatric Association).

\section{Results}

\section{Pharmacology of immediate and extended release quetiapine}

\section{Rationale and mode of action}

The receptor-binding properties of quetiapine are complex, and it appears unlikely that a single mechanism could explain the observed influence on major depression and anxiety disorders (Saller and Salama 1993; Richelson and Souder 2000).

The active metabolite of quetipiane, $\mathrm{N}$-desalkyl quetiapine, has a high affinity for the histamine $\mathrm{H}_{1}$ receptor and moderate affinities for the norepinephrine reuptake transporter (NET), the serotonin 5- $\mathrm{HT}_{1 \mathrm{~A}}, 5-\mathrm{HT}_{1 \mathrm{E}}, 5-\mathrm{HT}_{2 \mathrm{~A}}, 5-\mathrm{HT}_{2 \mathrm{~B}}, 5-\mathrm{HT}_{7}$ receptors, the $\alpha_{1 B}$-adrenergic receptor, and the $M_{1}, M_{3}$, and $M_{5}$ muscarinic receptors. The compound had low affinities for the $5-\mathrm{HT}_{1 \mathrm{D}}, 5-\mathrm{HT}_{2 \mathrm{C}}, 5-\mathrm{HT}_{3}, 5-\mathrm{HT}_{5}, 5-\mathrm{HT}_{6}, \alpha_{1 \mathrm{~A}}, \alpha_{2 \mathrm{~A}}, \alpha_{2 \mathrm{~B}}$, $\alpha_{2 \mathrm{C}}, \mathrm{H}_{2}, \mathrm{M}_{2}, \mathrm{M}_{4}$, and dopamine $\mathrm{D}_{1}, \mathrm{D}_{2}, \mathrm{D}_{3}$, and $\mathrm{D}_{4}$ receptors. 
N-Desalkyl quetiapine potently inhibited human NE transporter about 100-fold more potent than quetiapine itself. $\mathrm{N}$-desalkyl quetiapine was also 10 -fold more potent and more efficacious than quetiapine at the $5-\mathrm{HT}_{1 \mathrm{~A}}$ receptor. $\mathrm{N}$-Desalkyl quetiapine was an antagonist at $5-\mathrm{HT}_{2 \mathrm{~A}}, 5-\mathrm{HT}_{2 \mathrm{~B}}, 5-\mathrm{HT}_{2 \mathrm{C}}$, $\alpha_{1 \mathrm{~A}}, \alpha_{1 \mathrm{D}}, \alpha_{2 \mathrm{~A}}, \alpha_{2 \mathrm{C}}, \mathrm{H}_{1}, \mathrm{M}_{1}, \mathrm{M}_{3}$, and $\mathrm{M}_{5}$ receptors. A moderate affinity for the norepinephrine reuptake inhibitor transporter (NET) and partial $5 \mathrm{HT}_{\mathrm{A}}$ agonism, which are considered the possible reason for quetiapine's antidepressant effects as investigated in mouse experiment (Jensen et al 2008). The extent to which the N-desalkyl quetiapine metabolite contributes to the pharmacological activity of quetiapine in humans is not known.

In pre-clinical tests predictive of extrapyramidal symptoms (EPS), quetiapine is unlike standard antipsychotics and has an atypical profile. Quetiapine demonstrates selectivity for the limbic system by producing depolarisation blockade of the mesolimbic but not the nigrostriatal dopaminecontaining neurones following chronic administration. The results of these tests predict that quetiapine should have minimal EPS liability, may also have a lower liability to produce tardive dyskinesia (data on file, AstraZeneca Pharmaceuticals, Wilmington, DE, USA). The production of sustained elevations in prolactin, which is considered a feature of atypical agents, is not evident during quetiapine administration unlike most other antipsychotics (Atmaca et al 2002). However, a study by Alexiadis et al (2002) indicates that oral administration of quetiapine was associated with a marked but transient increase in serum prolactin levels. A recent study investigating the relationship between increased prolactin levels and sexual dysfunction showed that in this 6-week randomized double-blind trial, higher serum prolactin level was related to greater impairment of sexual functioning in male outpatients who were treated with risperidone. This effect was not seen in patient treated with quetiapine (Nakonezny et al 2007).

\section{Pharmacodynamics}

Quetiapine and the human plasma metabolite, N-desalkyl quetiapine, interact with a broad range of neurotransmitter receptors. Quetiapine, like clozapine, is an effective antipsychotic at lower $\mathrm{D}_{2}$ receptor occupancy which may account for its very low risk of EPS and prolactin elevation (Kapur et al 2000; Tauscher-Wisniewski et al 2002). Quetiapine and N-desalkyl quetiapine exhibit affinity for brain serotonin $\left(5 \mathrm{HT}_{2}\right)$ and dopamine $\mathrm{D}_{1}$ and $\mathrm{D}_{2}$ receptors. It is this combination of receptor antagonism with a higher selectivity for $5 \mathrm{HT}_{2}$ relative to $\mathrm{D}_{2}$ receptors which is believed to contribute to the clinical antipsychotic properties and low EPS liability of quetiapine (data on file, AstraZeneca Pharmaceuticals, Wilmington, DE, USA).

\section{Pharmacokinetics: absorption, metabolism,} distribution, elimination

Following oral administration quetiapine is extensively metabolized by the liver. Steady state peak molar concentrations of the active metabolite $\mathrm{N}$-desalkyl quetiapine are $35 \%$ of that observed for quetiapine. The pharmacokinetics of quetiapine and $\mathrm{N}$-desalkyl quetiapine are linear across the approved dosage range.

At daily doses of 450 to $600 \mathrm{mg}$ the $\mathrm{D}_{2}$ occupancy of quetipiane fumarate peaks within 2 to 3 hours of its administration (45\%-60\%) and quickly declines to less than $30 \%$ by 12 hours after the last oral dose (Gefvert et al 1998; Kapur et al 2000). Its rapid pharmacokinetics properties necessitate twice-daily dosing, which could lower adherence to the treatment (Iskedjian et al 2002; Diaz et al 2004). However, quetiapine immediate release is clinically also used at once-daily doses. The extended release formulation (XR) of quetiapine fumarate was developed with the goal of achieving similar efficacy and using a once-daily dosing regimen (Kahn et al 2007; Moller et al 2008). Compared to the immediate-release (IR) formulation (DeVane and Nemeroff 2001), the XR formulation shows a more gradual rise in plasma level $\left(\mathrm{t}_{\max }=6\right.$ hours $)$ and a slower decline over a 24-hour period $\left(\mathrm{t}_{1 / 2}=7\right.$ hours (data on file, AstraZeneca Pharmaceuticals, Wilmington, DE, USA).

Dose-proportional pharmacokinetics is displayed for doses of quetiapine XR of up to $800 \mathrm{mg}$ administered once daily. The maximum plasma concentration $\left(\mathrm{C}_{\max }\right)$ and the area under the plasma concentration-time curve (AUC) for quetiapine XR when administered once daily are comparable to those achieved for the same total daily dose of immediaterelease quetiapine fumarate administered twice daily.

Quetiapine is extensively metabolized by the liver and is approximately $83 \%$ bound to plasma proteins. In vitro investigations established that CYP3A4 is likely to be the primary enzyme responsible for cytochrome P450 mediated metabolism of quetiapine. $\mathrm{N}$-desalkyl quetiapine is primarily formed and eliminated via CYP3A4. CYP2D6 and CYP2C9 are also involved in quetiapine metabolism.

Quetiapine and several of its metabolites (including $\mathrm{N}$-desalkyl quetiapine) are weak to modest inhibitors of human cytochrome P450 3A4, 2C19, 2D6, 1A2 and 2C9 activities in vitro. From animal studies it appears that quetiapine can induce cytochrome P450 enzymes 
In a specific interaction study in psychotic patients, however, no increase in the cytochrome P450 activity was found after administration of quetiapine. The elimination half-lives of quetiapine and $\mathrm{N}$-desalkyl quetiapine are approximately 7 and 12 hours respectively (data on file, AstraZeneca Pharmaceuticals, Wilmington, DE, USA).

\section{Efficacy studies of quetiapine $X R$ in MDD and GAD Efficacy of quetiapine $X R$ in MDD}

The efficacy results of quetiapine XR in MDD are presented in Table 1. The six completed double-blind, randomized, placebo-controlled trials with quetipiane XR in MDD can be grouped into 1) monotherapy studies, 2) adjunct studies and 3) maintenance studies.

\section{Monotherapy studies of quetiapine XR in MDD}

In a 6-week, multicenter, double-blind, randomized, parallelgroup, placebo-controlled study evaluating the efficacy of Quetiapine XR (50, 150, and $300 \mathrm{mg}$ /day) as monotherapy in the treatment of patients with MDD, the primary endpoint was improvement on the Montgomery-Asberg Depression Rating Scale (MADRS) between randomization and week 6 (Weisler et al 2008a). A total of 723 adult patients were randomized: 182, 178, 179, and 184 to quetiapine XR 50, $150,300 \mathrm{mg} / \mathrm{day}$, and placebo, respectively. Mean scores at baseline were: MADRS 30.9, 30.9, 30.6, and 30.5; Hamilton Depression rating scale (HAM-D) 25.6, 25.5, 25.7, and 25.5; HAM-A 19.6, 19.4, 19.7, and 19.3, respectively. At week 6 , all quetiapine XR groups significantly reduced mean MADRS score vs placebo $(-11.07)$ : $-13.56(\mathrm{p} \leq 0.05)$ for $50 \mathrm{mg},-14.50(\mathrm{p} \leq 0.001)$ for $150 \mathrm{mg},-14.18(\mathrm{p} \leq 0.01)$ for $300 \mathrm{mg}$.

In a second trial, this time a 10 -week, double-blind, randomized, parallel-group, placebo-controlled study, the authors assessed the efficacy of quetiapine XR (150/300 mg/ day) as monotherapy for the treatment of MDD using a fixeddose regime (El-Khalili et al 2008a). A total of 310 patients were randomized to double-blind treatment: 154 quetiapine XR, 156 placebo. The primary endpoint was change from randomization to week 8 in MADRS total score. At week 8 , quetiapine XR significantly reduced mean MADRS score vs placebo $(-16.49$ vs $-13.10 ; \mathrm{p} \leq 0.01)$. MADRS response rates were significantly greater at week 8 for quetiapine XR vs placebo (61.9\% vs $48.0 \%$; $\mathrm{p} \leq 0.05)$.

In a third trial using a similar study design (8-week study, multicenter, double-blind, randomized, parallel-group, placebo-controlled) Montgomery et al (2008) investigated the efficacy of quetiapine XR (150 and $300 \mathrm{mg} /$ day) as monotherapy in the treatment of MDD utilizing an active control group of duloxetine $60 \mathrm{mg}$ /day (Montgomery et al 2008). In this study, 612 adult patients were randomized to receive quetiapine XR $150 \mathrm{mg} /$ day $(\mathrm{n}=152)$, quetiapine $300 \mathrm{mg} /$ day $(\mathrm{n}=152)$, duloxetine $60 \mathrm{mg} /$ day $(\mathrm{n}=151)$ and placebo $(\mathrm{n}=157)$. The primary endpoint was change in MADRS total score baseline at week 6 . Secondary variables included baseline to week 6 change in HAM-D total scores and Item 1 (depressed mood) scores. Mean MADRS total score (overall baseline mean, 30.15 ) was significantly reduced at week 6 the quetiapine XR $150 \mathrm{mg} /$ day, quetiapine $300 \mathrm{mg} /$ day and the duloxetine groups compared to the placebo group $(-14.81,-15.29,-14.64,-11.18$, respectively; $\mathrm{p} \leq 0.001)$. At week 6 , mean HAM-D total scores (overall baseline mean, 25.25) were significantly reduced vs placebo $(-10.26)$ in the quetiapine XR $150 \mathrm{mg} /$ day and $300 \mathrm{mg} /$ day groups $(-13.12,-14.02$, respectively, $\mathrm{p} \leq 0.001)$ and duloxetine $(-12.37, \mathrm{p} \leq 0.05)$. Mean HAM-D Item 1 scores (overall baseline mean, 3.03) were significantly reduced vs placebo (-1.07) by quetiapine XR $150 \mathrm{mg} /$ day, $300 \mathrm{mg} /$ day $(-1.49,-1.56$, respectively, $\mathrm{p} \leq 0.001)$ and duloxetine $(-1.53$, $\mathrm{p} \leq 0.001)$. Both MADRS response and remission rates were significantly higher in quetiapine XR $300 \mathrm{mg} /$ day and duloxetine as compared to placebo (Table 1). Quetiapine XR $150 \mathrm{mg}$ /day showed robust effects on remission rates in the study by Montgomery et al (2008).

\section{Maintenance treatment in MDD with quetiapine $\mathrm{XR}$ monotherapy}

The efficacy of quetiapine XR (50-300 mg/day) monotherapy was investigated in a maintenance treatment of patients with MDD in a 52-week, multicenter, double-blind, randomized-withdrawal, parallel-group, placebo-controlled study following an open-label stabilisation period (Datto et al 2008). Primary endpoint was the efficacy of quetiapine $\mathrm{XR}$ vs placebo in increasing time from randomization to depressed event as assessed by predefined criteria. A total of 787 patients were randomized to double-blind treatment: 391 quetiapine XR; 385 placebo. The risk of a depressed event was significantly reduced for quetiapine XR vs placebo (implying increased time to the event): $\mathrm{HR}=0.34$ $(0.25,0.46) ; \mathrm{p}<0.0001$. Over the study period, a total of 55 (14.2\%) quetiapine XR-treated and 132 (34.4\%) placebotreated patients experienced a depressed event.

\section{Adjunctive treatment with quetiapine $X R$}

Two randomized placebo controlled studies are reported, which examined the adjuvant effects of quetiapine. 


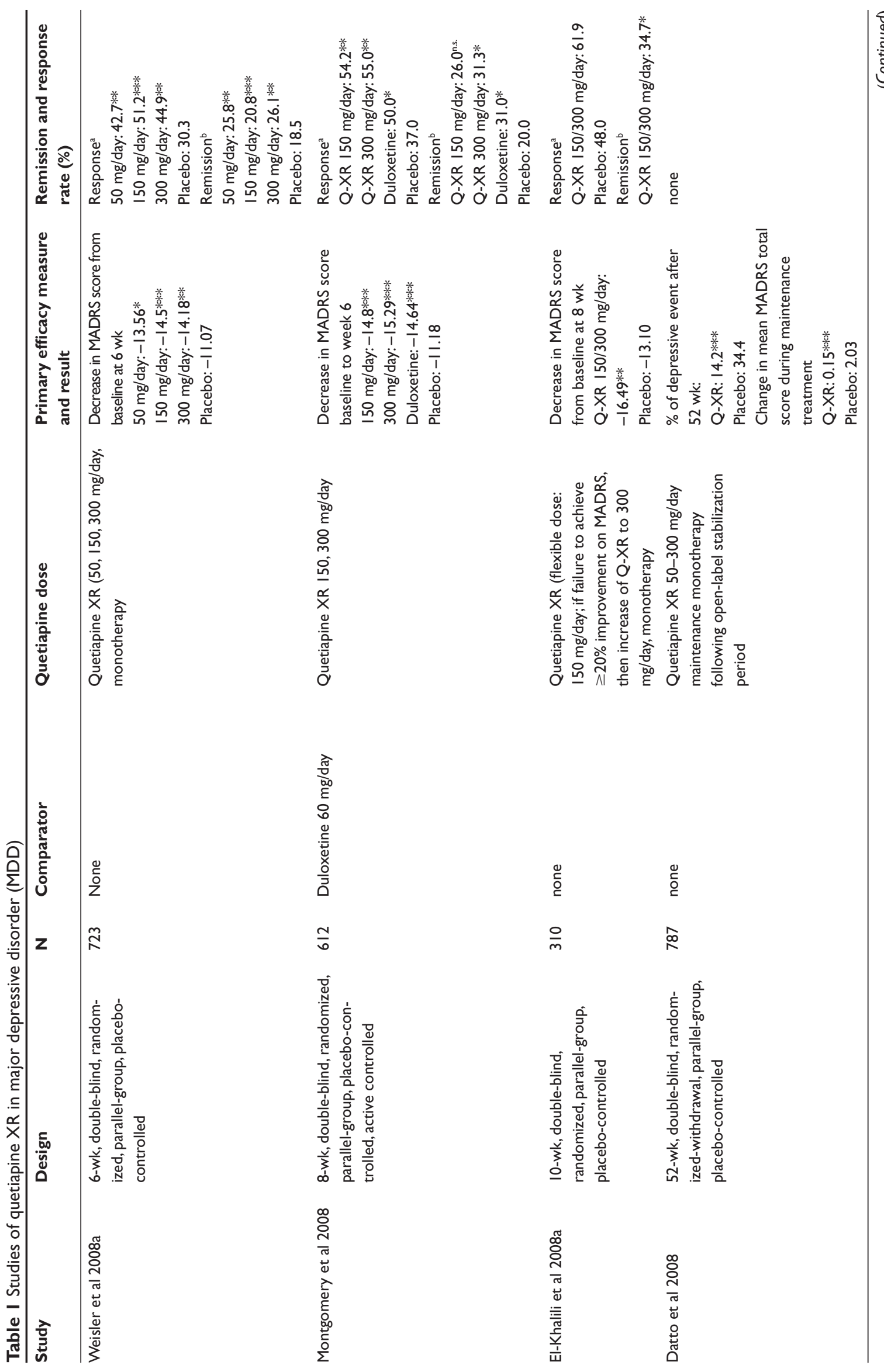




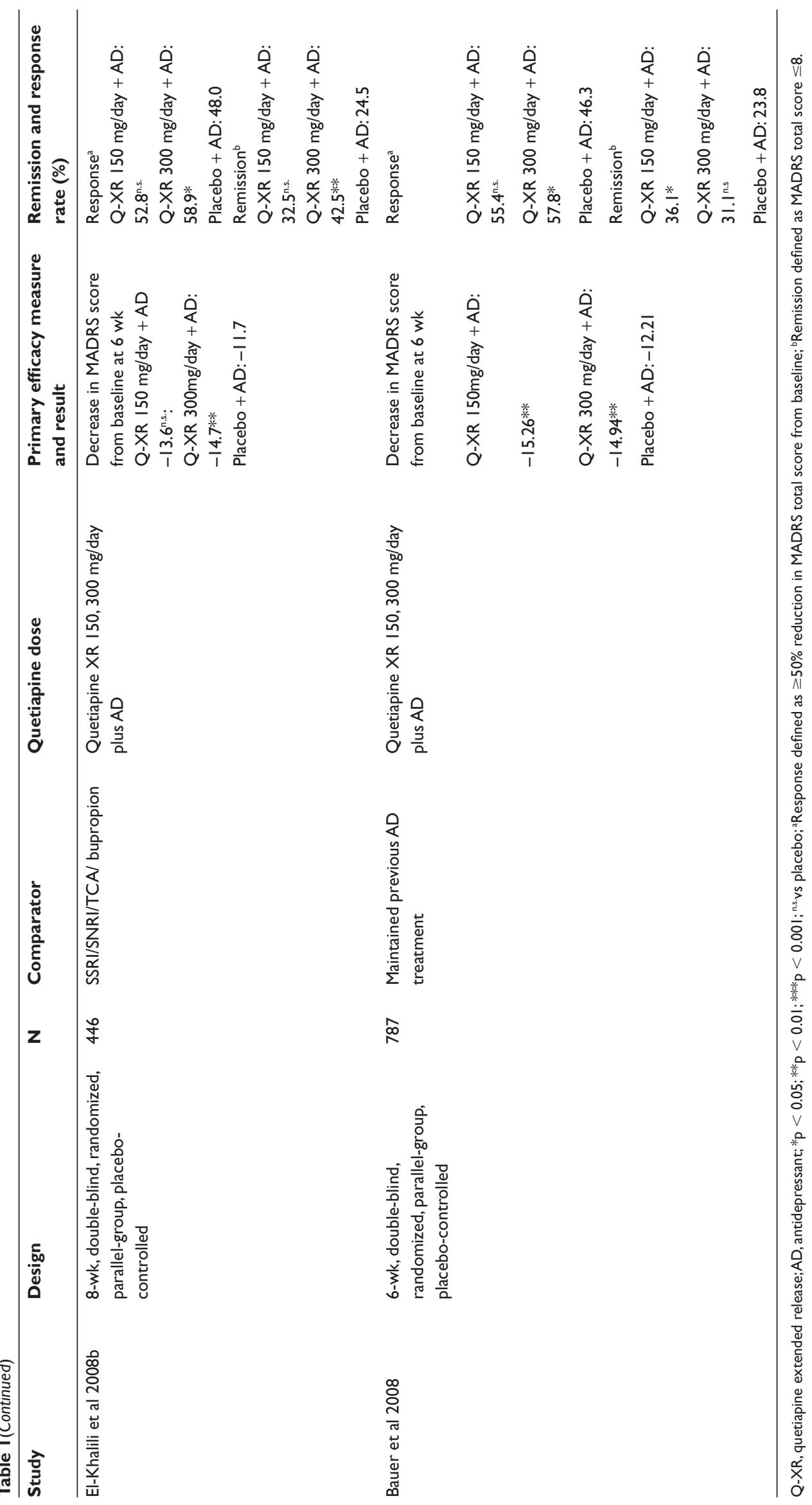


In an 8-week, multicenter, double-blind, randomized, parallel-group, placebo-controlled study the efficacy of Quetiapine XR (150 and $300 \mathrm{mg} /$ day) in combination with an antidepressant for the treatment of MDD and an inadequate response to previous antidepressant treatment was evaluated (El-Khalili et al 2008b). Patients received and antidepressant (SSRI/SNRI/TCA/bupropion) and either quetiapine XR $150 \mathrm{mg}$ /day, $300 \mathrm{mg}$ /day or placebo. The primary endpoint in this study was total change in MADRS score between randomization and week 6. A total of 446 patients were randomized: 148, 150, and 148 to quetiapine XR $150 \mathrm{mg} /$ day, $300 \mathrm{mg}$ /day and placebo, respectively. Mean baseline scores were: MADRS: 27.2, 27.6, and 27.6; HAM-D 24.0, 24.0, and 24.2, respectively. Quetiapine XR 300 mg/day + AD showed significant advantage vs placebo + AD for: 1) change in MADRS total score at week 6 (-14.70 vs $-11.7 ; \mathrm{p} \leq 0.01) ; 2$ ) improvement in MADRS from week 1 onwards; 3$)$ response $(58.9 \%$ vs $46.2 \%$; $\leq 0.05)$; 4 ) remission ( $42.5 \%$ vs $24.5 \%$; $\leq 0.01$ ). For quetiapine XR $150 \mathrm{mg} /$ day + AD improvements in these variables were not significantly different vs placebo.

The second adjunct study using a 6-week, double-blind, randomized, parallel-group, placebo-controlled study design evaluated the efficacy of quetiapine XR (150/300 mg/day) in combination with an antidepressant in the treatment of MDD in patients with an inadequate response to an antidepressant monotherapy. Previous antidepressant treatment was maintained. The primary endpoint was the change in MADRS total score between baseline and week 6 . As a result, mean change in MADRS total score (overall baseline mean, 28.4) from baseline to week 6 was significant $(\mathrm{p} \leq 0.01$ ) for quetiapine XR $150 \mathrm{mg} /$ day (-15.26) and $300 \mathrm{mg} /$ day (-14.94) vs placebo (-12.21). Results on response and remission were inconclusive (see Table 1).

\section{Efficacy of quetiapine $X R$ in GAD}

The efficacy results of quetiapine XR in GAD are presented in Table 2. While the three controlled published studies investigate quetiapine XR monotherapy in GAD, one of the controlled studies used an active control group of paroxetine.

\section{Monotherapy studies of short-term and long-term treatment with quetiapine $X R$ in GAD}

The first study is a 10-week, randomized, double-blind, parallel-group, placebo-controlled trial evaluating the efficacy of quetiapine $\mathrm{XR}(50,150$, and $300 \mathrm{mg} /$ day) compared with placebo in the treatment of GAD (Khan et al 2008).
The primary endpoint was total score change on the Hamilton Anxiety rating scale (HAM-A) from baseline to week 8 . Secondary endpoints included: HAM-A total score change from baseline to Week 1; HAM-A response and remission rates at week 8 . A total of 951 patients were randomized: quetiapine XR $50 \mathrm{mg} /$ day $(\mathrm{n}=234) ; 150 \mathrm{mg} /$ day $(\mathrm{n}=241)$; $300 \mathrm{mg} /$ day $(\mathrm{n}=241)$ or placebo $(\mathrm{n}=235)$. HAM-A total score mean change from baseline (overall baseline mean $24.6)$ to week 8 was significantly greater for $50 \mathrm{mg} /$ day $(-13.3, \mathrm{p} \leq 0.001)$ and $150 \mathrm{mg} /$ day $(-13.5, \mathrm{p} \leq 0.001)$ but not $300 \mathrm{mg} /$ day $(-11.9, \mathrm{p}=0.24)$ vs placebo $(-11.1)$. HAM-A response rates (week 8 ) were significantly higher for $50 \mathrm{mg}$ / day $(60.3 \%, \mathrm{p} \leq 0.05)$ and $150 \mathrm{mg} /$ day $(61.5 \%, \mathrm{p} \leq 0.05)$ but not $300 \mathrm{mg} /$ day $(54.9 \%, \mathrm{p}=0.37)$ vs placebo $(50.7 \%)$. HAM-A remission rates (week 8) were significantly higher for $150 \mathrm{mg} /$ day vs placebo $(37.2 \%$ vs $27.6 \%$, p $\leq 0.05)$; $50 \mathrm{mg} /$ day and $300 \mathrm{mg} /$ day remission rates were $36.1 \%$ $(\mathrm{p}=0.08)$ and $28.6 \%(\mathrm{p}=0.96)$, respectively.

In a second study, the long-term efficacy of quetiapine XR monotherapy following an open-label 1 period (50-300 mg/ day) in GAD was evaluated in a 52-week, double-blind, randomized-withdrawal, parallel-group, placebo-controlled clinical trial (Katzman et al 2008). Participants received quetiapine XR 4-8-week open-label followed by 12- to 18-week stabilization. Eligible patients (HAM-A $\leq 12$; MADRS $\leq 16$; CGI-S $\leq 3$ ) were randomized to quetiapine $\mathrm{XR}$ or placebo at last open-label visit dose, which subsequently could be adjusted to 50,150 , or $300 \mathrm{mg} /$ day as clinically indicated. The primary objective was to evaluate the efficacy of quetiapine XR vs placebo in increasing time from randomization to an anxiety event according to predefined criteria. Of the 433 patients who were randomized to double-blind treatment, half received quetiapine XR (216) and placebo (217). The risk of an event was significantly reduced for quetiapine XR vs placebo (implying increased time to the event): $\mathrm{HR}=0.19(0.12,0.31) ; \mathrm{p} \leq 0.0001$. Twenty-two quetiapine XR patients experienced an anxiety event which was a significantly lower percentage than the 84 placebo-treated patients who experienced an anxiety event $(10.2 \%$ vs $38.9 \%, p \leq 0.001)$. The study concluded that quetiapine XR monotherapy significantly reduced risk of relapse of anxiety events in patients with GAD.

\section{Adjunctive treatment with quetiapine $X R$}

This controlled trial was a 10 -week, randomized, doubleblind, parallel-group, placebo-controlled, active-controlled study evaluating the efficacy of quetiapine XR (50 and $150 \mathrm{mg} /$ day) compared with placebo for the treatment 


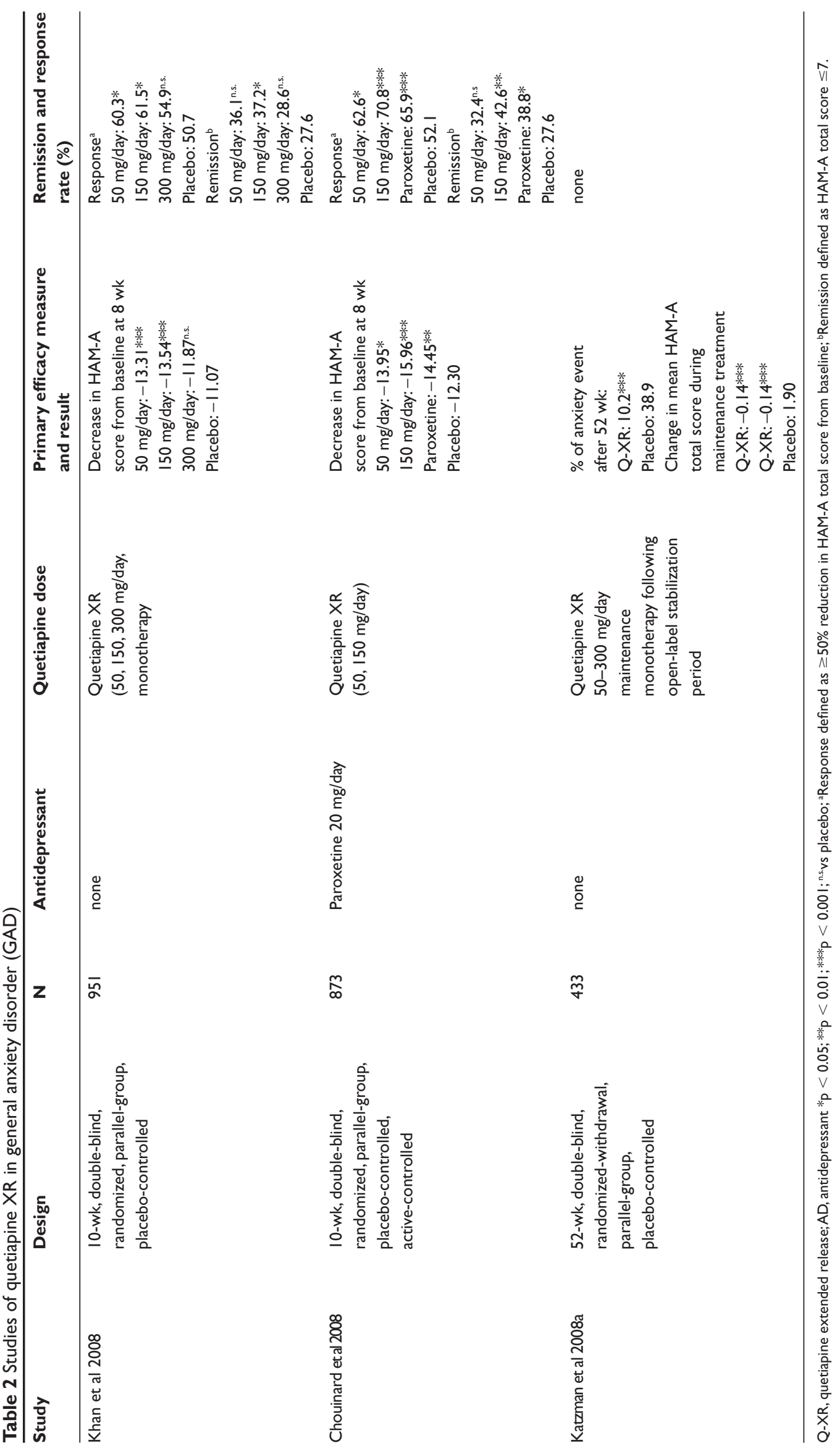


of GAD (Chouinard et al 2008). This study included an active control group of paroxetine $20 \mathrm{mg}$ /day. The primary endpoint employed in this study was the HAM-A total score change from baseline to week 8 and the secondary endpoint considered response and remission criteria. In total, 873 patients were randomized to quetiapine XR $50 \mathrm{mg} /$ day $(\mathrm{n}=221), 150 \mathrm{mg} /$ day $(\mathrm{n}=218)$, paroxetine $20 \mathrm{mg} /$ day $(\mathrm{n}=217)$, or placebo $(\mathrm{n}=217)$. Mean HAM-A total score (baseline mean, 26.98) was significantly decreased at day 4 by both quetiapine XR doses $(\mathrm{p} \leq 0.05)$ and at week 8 by quetiapine XR $50 \mathrm{mg} /$ day $(-13.95, \mathrm{p} \leq 0.05), 150 \mathrm{mg} /$ day $(-15.96, \mathrm{p} \leq 0.001)$, and paroxetine $(-14.45, \mathrm{p} \leq 0.01) \mathrm{vs}$ placebo (-12.30). Quetiapine XR at both doses as well as paroxetine showed significantly higher response and remission rates (except quetiapine XR $50 \mathrm{mg}$ for remission rates) as presented in Table 2.

\section{Safety, tolerability, and adherence in treatment with quetiapine}

It has been demonstrated that quetiapine monotherapy is well tolerated for the treatment of bipolar depression (BOLDER study) (Calabrese et al 2005). In this particular study, extrapyramidal symptoms were assessed with the Simpson-Angus Rating Scale (Simpson and Angus 1970), and akathisia was assessed with the Barnes Rating Scale for Drug-Induced Akathisia (Barnes 1989). The most common side effects of quetiapine included dry mouth, sedation, somnolence, dizziness, and constipation. The most common side effects leading to withdrawal from the study were sedation and somnolence, with most discontinuations occurring within the first week. The most common reasons for withdrawal were related to adverse events in the quetiapine groups (300/600 mg/day) (26.1\% and $16.0 \%)$ and lack of efficacy in the placebo group (13.3\%) (Calabrese et al 2005).

Of importance, changes in weight observed were relatively small and did not result in withdrawal from the study (Calabrese et al 2005). More specifically, during the quetiapine monotherapy study performed by Weisler et al patients in the quetiapine XR $50(\mathrm{n}=178), 150(\mathrm{n}=168)$, and $300 \mathrm{mg} /$ day $(\mathrm{n}=176)$ groups experienced a mean weight change of $+0.6 \mathrm{~kg},+0.9 \mathrm{~kg}$, and $1.0 \mathrm{~kg}$, respectively, while patients in the placebo group $(n=178)$ experienced a mean weight change of $+0.6 \mathrm{~kg}$. The proportion of patients experiencing $\geq 7 \%$ increase in weight was $0.6 \%, 3.6 \%$, $4.5 \%$, and $1.1 \%$ for $50,150,300 \mathrm{mg} /$ day quetiapine $\mathrm{XR}$, and placebo, respectively (Weisler et al 2008a).

Quetiapine treatment was not associated with treatmentemergent mania. Furthermore, adverse events considered extra-pyramidal symptoms were present in $8.9 \%$ of the $600 \mathrm{mg}$ /day group, $6.7 \%$ of the $300 \mathrm{mg}$ /day group, and $2.2 \%$ of the placebo group; discontinuation rates for extra-pyramidal symptoms were $2.8 \%, 1.1 \%$, and $0.6 \%$, respectively.

The side effect profile of quetiapine was assessed in detail in studies by Datto et al (2008) and Montgomery et al (2008) assessing the efficacy of quetiapine XR on MDD. While Table 3 shows that quetiapine XR was more frequently related to dry mouth, sedation, and somnolence than duloxetine and placebo in an 8-week trial, results on adverse events presented in Table 4 indicate that those typical side effects are similar in pattern but slightly less common in long-term treatment of up to 52 weeks with quetiapine. Interestingly, the adverse events reported do not indicate a dose-response relationship for quetiapine XR $150 \mathrm{mg}$ and $300 \mathrm{mg}$. In all of the above reported studies evaluating the efficacy of quetiapine XR in MDD and GAD no changes on ECG parameters between treatment and placebo were reported.

\section{Impact of quetiapine $X R$ on quality of life}

Health-related quality of life measures obtained in randomized-controlled trials are reported for some of the GAD studies. In the studies by Chouinard and by Katzmann quality of life was measured using the Quality of Life Enjoyment and Satisfaction Questionnaire (Q-LES-Q). After adjustment for multiplicity (quetiapine groups only), significant increases in Q-LES-Q percent maximum possible total score were seen with quetiapine XR $150 \mathrm{mg}$ and paroxetine compared with placebo at week $8(13.19,10.85$, and 7.44 , respectively) (Chouinard et al 2008) (Figure 1). Similarly, in the study by Katzmann et al (in press) health-related quality of life enjoyment and satisfaction was better with quetiapine XR compared with the placebo group.

\section{Conclusions}

While quetiapine has demonstrated efficacy in schizophrenia and bipolar disorder as well as in the treatment of specific symptoms clusters such as agitation and sleep problems in mood disorders, most recent randomized controlled studies show efficacy, safety and tolerability of quetiapine in major depressive disorder and general anxiety disorder, as evaluated in this review. The efficacious application of quetiapine in MDD and GAD ranges from quetiapine monotherapy to adjunctive therapy with antidepressants for shortterm and maintenance treatment at a dose range between $50-300 \mathrm{mg} /$ day. The dual action of quetipiane and its active metabolite $\mathrm{N}$-desalkyl quetiapine on the norepinephrine 
Table 3 Most common adverse events (AEs) ( $>5 \%$ in any group) during the active treatment period (safety population)

\begin{tabular}{|c|c|c|c|c|}
\hline AE, n (\%) & Placebo $(n=157)$ & $\begin{array}{l}\text { Quetiapine XR } 150 \mathrm{mg} / \text { day } \\
(\mathrm{n}=152)\end{array}$ & $\begin{array}{l}\text { Quetiapine XR } 300 \mathrm{mg} / \text { day } \\
(\mathrm{n}=152)\end{array}$ & $\begin{array}{l}\text { Duloxetine } \\
(\mathrm{n}=179)\end{array}$ \\
\hline Dry mouth & $14(8.9)$ & $51(33.6)$ & $58(38.2)$ & $28(18.8)$ \\
\hline Sedation & $8(5.1)$ & $59(38.8)$ & $56(36.8)$ & $24(16.1)$ \\
\hline Somnolence & II (7.0) & $37(24.3)$ & 4 I (27.0) & $19(12.8)$ \\
\hline Dizziness & $17(10.8)$ & $22(14.5)$ & $29(19.1)$ & $25(16.8)$ \\
\hline Headache & $16(10.2)$ & $16(10.5)$ & $14(9.2)$ & $27(18.1)$ \\
\hline Constipation & $10(6.4)$ & $9(5.9)$ & $13(8.6)$ & $17(11.4)$ \\
\hline Irritability & $7(4.5)$ & $2(1.3)$ & $9(5.9)$ & 0 \\
\hline Dyspepsia & $5(3.2)$ & $6(3.9)$ & $8(5.3)$ & $8(5.4)$ \\
\hline Fatigue & 0 & $4(2.6)$ & $8(5.3)$ & $10(6.7)$ \\
\hline Nausea & $15(9.6)$ & $16(10.5)$ & $8(5.3)$ & $54(36.2)$ \\
\hline Vision blurred & $3(1.9)$ & $8(5.3)$ & $8(5.3)$ & $4(2.7)$ \\
\hline Increased appetite & $3(1.9)$ & $9(5.9)$ & $6(3.9)$ & $3(2.0)$ \\
\hline Diarrhea & $10(6.4)$ & $7(4.6)$ & $4(2.6)$ & $16(10.7)$ \\
\hline $\begin{array}{l}\text { Upper respiratory } \\
\text { tract infection }\end{array}$ & II (7.0) & $3(2.0)$ & $4(2.6)$ & $6(4.0)$ \\
\hline Abnormal dreams & I $(0.6)$ & $10(6.6)$ & $3(2.0)$ & $4(2.7)$ \\
\hline Pollakiuria & $2(1.3)$ & $5(3.3)$ & $3(2.0)$ & $8(5.4)$ \\
\hline Insomnia & II (7.0) & $2(1.3)$ & $2(1.3)$ & $22(14.8)$ \\
\hline Decreased appetite & I (0.6) & $5(3.3)$ & 0 & $8(5.4)$ \\
\hline Hyperhidrosis & I $(0.6)$ & 0 & 0 & II (7.4) \\
\hline
\end{tabular}

reuptake inhibitor transporter (NET) and the $5 \mathrm{HT} 1_{\mathrm{A}}$ receptor is considered the possible reason for quetiapine's antidepressant effects.

Quetiapine appears to have a specific but overall mild side-effect profile. Some adverse effects such as sedation and somnolence may however lead to withdrawal from treatment in some patients. Despite the often beneficial sedative effects of quetiapine on clinically relevant sleep problems in psychiatric patients, quetipaine is not recommended soley as a sleeping agent. Overall, the most recently available evidence on quetiapine suggests that it can play a significant role in the management of MDD and GAD.

Table 4 Most common adverse events (AEs) (>5\%) occurring in any group during the open-label and randomization treatment phases (safety population)

\begin{tabular}{llll}
\hline Preferred term, $\mathbf{n}(\%)$ & Open-label phase & Randomized phase & Quetiapine XR (n= 39I) \\
\cline { 2 - 4 } & Quetiapine XR $(\mathbf{n}=\mathbf{1 0 7 8})$ & Placebo $(\mathbf{n}=\mathbf{3 8 5})$ & $14(3.6)$ \\
\hline Dry mouth & $259(24.0)$ & $6(1.6)$ & $15(3.8)$ \\
Somnolence & $362(33.6)$ & 0 & $10(2.6)$ \\
Sedation & $218(20.2)$ & $1(0.3)$ & $26(6.6)$ \\
Dizziness & $142(13.2)$ & $17(4.4)$ & $17(4.3)$ \\
Fatigue & $152(14.1)$ & $10(2.6)$ & $38(9.7)$ \\
Weight increased & $68(6.3)$ & $6(1.6)$ & $27(6.9)$ \\
Headache & $93(8.6)$ & $44(11.4)$ & $8(2.0)$ \\
Constipation & $70(6.5)$ & $1(0.3)$ & $14(3.6)$ \\
Nausea & $62(5.8)$ & $38(9.9)$ & $3(0.8)$ \\
Irritability & $93(8.6)$ & $12(3.1)$ & $28(7.2)$ \\
Nasopharyngitis & $23(2.1)$ & $25(6.5)$ & $22(5.6)$ \\
Insomnia & $37(3.4)$ & $57(14.8)$ & $21(5.4)$ \\
Diarrhea & $24(2.2)$ & $26(6.8)$ & \\
\hline
\end{tabular}




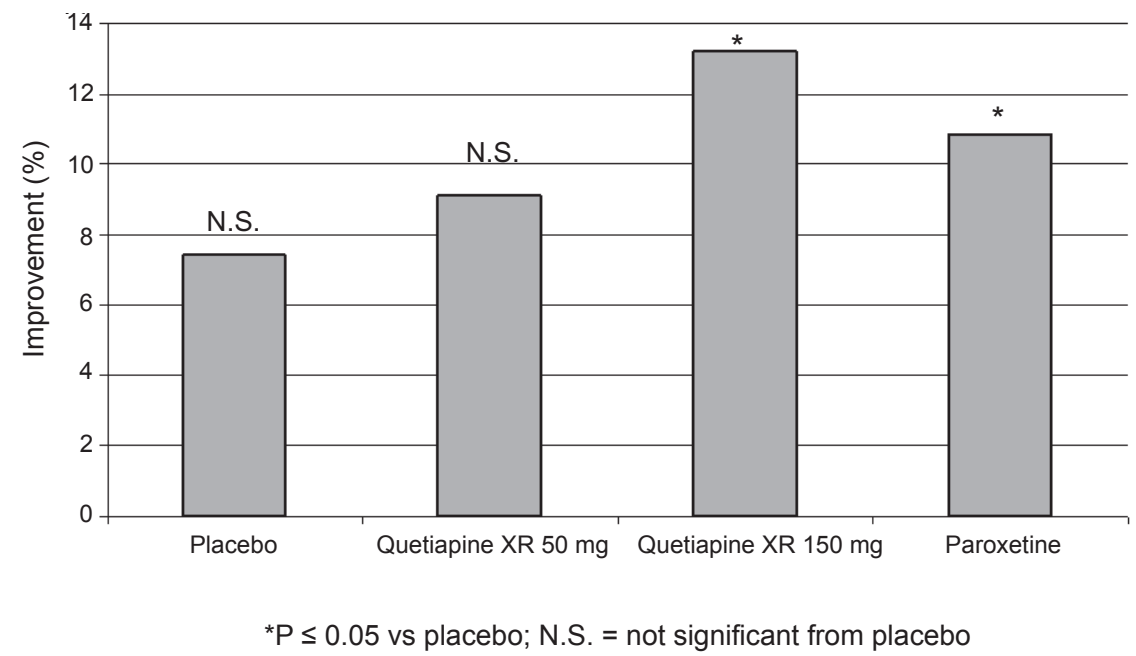

Figure I Improvement of quality of life measures in patients with generalized anxiety disorder.

\section{Acknowledgments}

The author is grateful for the contribution of Veronica DuBois and Riccardo Caniato during the editing process of the manuscript.

\section{Disclosures}

BT Baune has received grants from the National Health and Medical Research Council (NHMRC, Australia). He has received honoraria ( $<\$ 1,000$ US from each) for educational training of psychiatrists and general practitioners from Lundbeck, Astra Zeneca and Pfizer Pharmaceuticals. He has received travel grants for attending congresses from Astra Zeneca, Bristol-Meyer Squibb, Janssen and Pfizer Pharmaceuticals. The author declares no conflict of interest.

\section{References}

Alexiadis M, Whitehorn D, Woodley H, et al. 2002. Prolactin elevation with quetiapine. Am J Psychiatry, 159:1608-9.

Ananth J. 1998. Treatment-resistant depression. Psychother Psychosom, 67:61-70.

Arango C, Bernardo M. 2005. The effect of quetiapine on aggression and hostility in patients with schizophrenia. Hum Psychopharmacol, 20:237-41.

Atmaca M, Kuloglu M, Tezcan E, et al. 2002. Quetiapine is not associated with increase in prolactin secretion in contrast to haloperidol. Arch Med Res, 33:562-5.

Barnes TR. 1989. A rating scale for drug-induced akathisia. Br J Psychiatry, 154: $672-6$.

Baune BT, Caliskan S, Todder D. 2007. Effects of adjunctive antidepressant therapy with quetiapine on clinical outcome, quality of sleep and daytime motor activity in patients with treatment-resistant depression. Hum Psychopharmacol, 22:1-9.

Berk M, Dodd S. 2005. Efficacy of atypical antipsychotics in bipolar disorder. Drugs, 65:257-69.

Calabrese JR, Keck PE Jr, Macfadden W, et al. 2005. A randomized, double-blind, placebo-controlled trial of quetiapine in the treatment of bipolar I or II depression. Am J Psychiatry, 162:1351-60.
Chouinard G, Ahokas A, Bandelow B, et al. 2008. Once-daily extended release quetiapine fumarate (quetiapine $\mathrm{XR}$ ) monotherapy in generalized anxiety disorder (GAD): a placebo-controlled study with active-comparator paroxetine. Anxiety Disorders Association of America Congress. Savannah, Georgia, USA.

Cohrs S, Rodenbeck A, Guan Z, et al. 2004. Sleep-promoting properties of quetiapine in healthy subjects. Psychopharmacology (Berl), 174:421-9.

Croissant B, Klein O, Gehrlein L, et al. 2006. Quetiapine in relapse prevention in alcoholics suffering from craving and affective symptoms: a case series. Eur Psychiatry, 21:570-3.

Dando TM, Keating GM. 2005. Quetiapine: a review of its use in acute mania and depression associated with bipolar disorder. Drugs, 65:2533-51.

Dannlowski U, Baune BT, Bockermann I, et al. in press. Adjunctive antidepressant treatment with quetiapine in agitated depression: positive effects on symptom reduction, psychopathology and remission rates. Hum Psychopharmacol.

Datto C, Lam R, Lepola U, et al. 2008. Double-blind study of extended release quetiapine fumarate (quetiapine XR) monotherapy for maintenance treatment of major depressive disorder (MDD). 161st Annual Meeting of the American Psychiatric Association. Washington DC, USA.

DeVane CL, Nemeroff CB. 2001. Clinical pharmacokinetics of quetiapine: an atypical antipsychotic. Clin Pharmacokinet, 40:509-22.

Diaz E, Neuse E, Sullivan MC, Pearsall HR. and Woods SW. 2004. Adherence to conventional and atypical antipsychotics after hospital discharge. J Clin Psychiatry, 65: 354-60.

Doree JP, Des Rosiers J, Lew V, et al. 2007. Quetiapine augmentation of treatment-resistant depression: a comparison with lithium. Curr Med Res Opin, 23:333-41.

El-Khalili N, Banov M, Bortnick B, et al. 2008a. Efficacy and tolerability of extended release quetiapine fumarate (quetiapine XR) monotherapy in major depressive disorder (MDD): a randomized, placebo-controlled clinical trial (Study 003). 63rd Annual Society of Biological Psychiatry. Washington DC, USA.

El-Khalili N, Joyce M, Atkinson S, et al. 2008b. Adjunctive extended-release quetiapine fumarate (quetiapine XR) in patients with major depressive disorder and inadequate antidepressant response. 161st Annual Meeting of the American Psychiatric Association. Washington DC, USA

Fava M, Davidson KG. 1996. Definition and epidemiology of treatmentresistant depression. Psychiatr Clin North Am, 19:179-200.

Ferrier IN. 1999. Treatment of major depression: is improvement enough? J Clin Psychiatry, 60(Suppl 6):10-4. 
Gao K, Muzina D, Gajwani P, et al. 2006. Efficacy of typical and atypical antipsychotics for primary and comorbid anxiety symptoms or disorders: a review. J Clin Psychiatry, 67:1327-40.

Gefvert O, Bergstrom M, Langstrom B, et al. 1998. Time course of central nervous dopamine-D2 and 5-HT2 receptor blockade and plasma drug concentrations after discontinuation of quetiapine (Seroquel) in patients with schizophrenia. Psychopharmacology (Berl), 135:119-26.

Ghaemi SN, Katzow JJ. 1999. The use of quetiapine for treatment-resistant bipolar disorder: a case series. Ann Clin Psychiatry, 11:137-40.

Hanley MJ, Kenna GA. 2008. Quetiapine: treatment for substance abuse and drug of abuse. Am J Health Syst Pharm, 65:611-8.

Hirschfeld RM, Weisler RH, Raines SR, et al. 2006. Quetiapine in the treatment of anxiety in patients with bipolar I or II depression: a secondary analysis from a randomized, double-blind, placebo-controlled study. J Clin Psychiatry, 67:355-62.

Iskedjian M, Einarson TR, Mackeigan LD, et al. 2002. Relationship between daily dose frequency and adherence to antihypertensive pharmacotherapy: evidence from a meta-analysis. Clin Ther, 24:302-16.

Jensen NH, Rodriguiz RM, Caron MG, et al. 2008. N-desalkylquetiapine, a potent norepinephrine reuptake inhibitor and partial 5-HT1A agonist, as a putative mediator of quetiapine's antidepressant activity. Neuropsychopharmacology, 33:2303-12.

Kahn RS, Schulz SC, Palazov VD, et al. 2007. Efficacy and tolerability of once-daily extended release quetiapine fumarate in acute schizophrenia: a randomized, double-blind, placebo-controlled study. J Clin Psychiatry, 68:832-42.

Kapur S, Zipursky R, Jones C, et al. 2000. A positron emission tomography study of quetiapine in schizophrenia: a preliminary finding of an antipsychotic effect with only transiently high dopamine D2 receptor occupancy. Arch Gen Psychiatry, 57:553-9.

Katzman MA, Vermani M, Jacobs L, et al. in press. Quetiapine as an adjunctive pharmacotherapy for the treatment of non-remitting generalized anxiety disorder: A flexible-dose, open-label pilot trial. $J$ Anxiety Disord.

Katzman M, Brawman-Mintzer O, Reyes E, et al. 2008. Extended release quetiapine fumarate (quetiapine XR) monotherapy in maintenance treatment of generalized anxiety disorder (GAD): efficacy and tolerability results from a randomized, placebo-controlled trial. 63rd Annual Society of Biological Psychiatry. Washington, DC, USA

Keating GM, Robinson DM. 2007. Quetiapine: a review of its use in the treatment of bipolar depression. Drugs, 67:1077-95.

Kennedy SH, Lam R. W. 2003. Enhancing outcomes in the management of treatment resistant depression: a focus on atypical antipsychotics. Bipolar Disord, 5(Suppl 2):36-47.

Khan A, Joyce M, Eggens I, et al. 2008. Extended release quetiapine fumarate (quetiapine XR) monotherapy in the treatment of patients with generalized anxiety disorder (GAD). Anxiety Disorders Association of America Congress. Savannah, Georgia, USA.

Khazaal Y, Tapparel S, Chatton A, et al. 2007. Quetiapine dosage in bipolar disorder episodes and mixed states. Prog Neuropsychopharmacol Biol Psychiatry, 31:727-30.

Moller HJ, Johnson S, Mateva T, et al. 2008. Evaluation of the feasibility of switching from immediate release quetiapine to extended release quetiapine fumarate in stable outpatients with schizophrenia. Int Clin Psychopharmacol, 23:95-105.

Montgomery S, Cutler A, Lazarus A, et al. 2008. Extended release quetiapine fumarate (quetiapine XR) monotherapy in the treatment of patients with major depressive disorder (MDD). 16th European Congress of Psychiatry. Nice, France.
Nakonezny PA, Byerly MJ, Rush AJ. 2007. The relationship between serum prolactin level and sexual functioning among male outpatients with schizophrenia or schizoaffective disorder: a randomized double-blind trial of risperidone vs quetiapine. J Sex Marital Ther, 33:203-16.

Nemeroff CB. 2005. Use of atypical antipsychotics in refractory depression and anxiety. J Clin Psychiatry, 66(Suppl 8):13-21.

Nierenberg AA, Wright EC. 1999. Evolution of remission as the new standard in the treatment of depression. J Clin Psychiatry, 60(Suppl 22):7-11.

Philip NS, Carpenter LL, Tyrka AR, et al. 2008. Augmentation of antidepressants with atypical antipsychotics: a review of the current literature. J Psychiatr Pract, 14:34-44.

Richelson E, Souder T. 2000. Binding of antipsychotic drugs to human brain receptors focus on newer generation compounds. Life Sci, 68:29-39.

Rush A, Trivedi MT. 1995. Treating depression to remission. Psychiatr Ann, 9:704-5.

Sagud M, Mihaljevic-Peles A, Muck-Seler D, et al. 2006. Quetiapine augmentation in treatment-resistant depression: a naturalistic study. Psychopharmacology (Berl), 187:511-4

Saller CF, Salama AI. 1993. Seroquel: biochemical profile of a potential atypical antipsychotic. Psychopharmacology (Berl), 112:285-92.

Sattar SP, Bhatia SC, Petty F. 2004. Potential benefits of quetiapine in the treatment of substance dependence disorders. J Psychiatry Neurosci, 29:452-7.

Savaskan E, Schnitzler C, Schroder C, et al. 2006. Treatment of behavioural, cognitive and circadian rest-activity cycle disturbances in Alzheimer's disease: haloperidol vs. quetiapine. Int $J$ Neuropsychopharmacol, 9:507-16.

Shelton RC, Papakostas GI. 2008. Augmentation of antidepressants with atypical antipsychotics for treatment-resistant major depressive disorder. Acta Psychiatr Scand, 117:253-9.

Simpson GM, Angus JW. 1970. A rating scale for extrapyramidal side effects. Acta Psychiatr Scand Suppl, 212:11-9.

Sokolski KN, Denson TF. 2003. Adjunctive quetiapine in bipolar patients partially responsive to lithium or valproate. Prog Neuropsychopharmacol Biol Psychiatry, 27:863-6.

Srisurapanont M, Maneeton B, Maneeton N. 2004. Quetiapine for schizophrenia. Cochrane Database Syst Rev, CD000967.

Tauscher-Wisniewski S, Kapur S, Tauscher J, et al. 2002. Quetiapine: an effective antipsychotic in first-episode schizophrenia despite only transiently high dopamine-2 receptor blockade. J Clin Psychiatry, 63:992-7.

Thase ME, Macfadden W, Weisler RH, et al. 2006. Efficacy of quetiapine monotherapy in bipolar I and II depression: a doubleblind, placebo-controlled study (the BOLDER II study). J Clin Psychopharmacol, 26:600-9.

Todder D, Caliskan S, Baune BT. 2006. Night locomotor activity and quality of sleep in quetiapine-treated patients with depression. J Clin Psychopharmacol, 26:638-42.

Vieta E. 2005. Mood stabilization in the treatment of bipolar disorder: focus on quetiapine. Hum Psychopharmachol, 3: [Epub ahead of print].

Weisler RH, Calabrese JR, Thase ME, et al. 2008b. Efficacy of quetiapine monotherapy for the treatment of depressive episodes in bipolar I disorder: a post hoc analysis of combined results from 2 double-blind, randomized, placebo-controlled studies. J Clin Psychiatry, 69:769-82.

Weisler R, Joyce M, McGill L, et al. 2008a. Extended release quetiapine fumarate (quetiapine XR) monotherapy for major depressive disorder (MDD): a double-blind, placebo-controlled study. American Psychiatric Association. Washington, DC, USA. 